\section{Speech and language defects}

SIR-In a recent Scientific Correspondence', Gopnik presented findings on specific language impairment (as 'developmental dysphasia' is more often called) in various members of a large family. These linguistic deficits are attributed to the impairment of one particular grammatical faculty, and the problem termed 'feature blindness' by Gopnik.

'Feature blindness' is to be understood as a grammatical competence deficit, which will manifest itself across a range of linguistic performance tasks. Gopnik also suggests that the errors her subjects make could be more generally typical of language-impaired individuals. An explanatory account of specific language impairment derived from grammatical theory, and linked to genetic factors, would be an exciting development. There are reasons, however, to be cautious about Gopnik's claims.

Specific language impairment, outside the family studied, takes on more diverse forms than Gopnik envisages. Recent reports have identified, in impaired individuals within the age-range of Gopnik's subjects, problems with verb complementation $^{2}$, temporal adverbials ${ }^{3}$ and complex sentence formation ${ }^{4}$. These areas of the grammar seem to fall outside the purview of Gopnik's hypothesis, and so her explanation cannot hold for specific language impairment more generally considered.

It is not clear that the restricted type of impairment in the affected family members can be explained only as a deficit in the underlying grammar. For example, a median score of 18 is reported for the language-impaired group (compared with 29 for normals) on a test of grammatical features (forms like plural, past tense and third-person singular). The groups do seem to be distinct on this presumably key measure of Gopnik's hypothesis.

But how is it that half of the impaired group is able to achieve a score of 60 per cent or more on this test if they are feature-blind? This is a high level of performance for an individual who has an underlying grammatical deficit in this area. It would seem more sensible to use the term 'feature-impaired', and to consider the possibility, documented elsewhere ${ }^{5}$, that the more likely source of the variable performance problems lies in the language-production processing system, rather than in the underlying grammar.

Grammatical forms like plural, past tense and third person singular are particularly vulnerable, in English, in individuals with phonological production prob-

\section{Gopnik, M. Nature 344, 715 (1990).}

2. Fletcher, $\mathrm{P}$. in Research in Child Language Disorders: $A$ Decade of Progress (ed Miller, J.) 171-189 (Pro-Ed, Austin, 1990).

3. Crystal, D. Linguistic Encounters with Language Handi cap. 97-103 (Blackwell, Oxford, 1984).

4. Fletcher, P. \& Garman, M. Clin. Ling. Phonet. 2, 97-113 (1988).

5. Chiat, S. \& Hirson, A. Br. J. disord. Commun. 22, 37 (1987)

\title{
Fractal magmatic systems
}

SiR-It seems reasonable to imagine a magmatic system as a complex network of fractures, veins and veinlets, ranging in size from that of the feeding dykes down to that of intergranular films. I conjecture that, like that of a blood-vessel system ${ }^{1}$, the geometry of a magma conduit system can be described much better as a fractal ${ }^{2}$ than as a euclidean shape.

Spera showed that there are thermal constraints on magma ascent ${ }^{3.4}$. The raising magma gives off heat to the cool lithosphere and undergoes 'heat death' and freezing, unless the ascent velocity is high and/or the feeding dyke is large. When the melt starts to move towards the surface, the smallest veins quickly freeze and release fluids. If these are collected by the melt in an immediately larger network, the ascent of the remaining magma is easier because hydrous fluids decrease both magma density ${ }^{5}$ and viscosity ${ }^{6}$, thus tending to increase buoyancy and to decrease friction forces. The process continues all the way to the surface, and its extent depends on the local lithospheric thermal regime ${ }^{7}$. Heat death of a part of the magma may help the rest of the magma to make its way to the surface. The magmatic structure, like that of a root, is

expected to be more finely ramified at depth; at shallow depth it may have reduced itself to a single dyke.

The surviving magma is enriched in elements which have a strong affinity for $\mathrm{CO}_{2}-\mathrm{H}_{2} \mathrm{O}$ fluid phases. Mobile elements like radium (see refs 8,9 ) are extracted at a microscopic scale from a much larger mantle volume than the major elements. Their enrichment in the final magma is a function of their affinity for the fluid phase and of the efficiency of the extraction process.

Dipartimento di Scienze della Terra,

Università di Napoli Federico II,

Largo S. Marcellino 10,

80138 Napoli, Italy

\footnotetext{
1. Grebogi, C., McDonald, S.W., Ott, E. \& Yorke, J.A. Phys. Lett. 110A, 1-4 (1985)

Mandelbroth, B.B. The Fracta man, San Francisco, 1983)

3. Bottinga, Y. \& Weill, D.F. Am. J. Sci. 260, 169-182 (1970).

4. Shaw, H.R. Am. J. Sci. 272, 870-893 (1972).

5. Spera, F.J. Contrib. Mineral. Petrol. 88, 217-232 (1984)

. Spera, F.J. in Mantle Metasomatism. (eds Menzies, M.A. \& Hawkesworth, C.J.) 1-20 (Academic, London, 1987).

Bruce, P. M. \& Huppert, H.E Nature 342, 665-667 (1989).

8. Rubin, H.K. \& Macdonald, J.D. Nature 335, 158 (1988)

9. Cortini, M. in Uranium - Geochemistry, Mineralogy, Exploration and Resources (eds De Vivo, B., Ippolito, F. Capaldi, G. \& Simpson, P.R.) 4-11 (Institution for Mining
} and Metallurgy, London, 1984). lems. Was the phonological ability of the subjects reviewed, and eliminated as a factor in the impairment of some or all of them? Until alternative explanations have been explicitly considered, there must be some scepticism about Gopnik's thesis.

PAUL FLETCHER

Department of Linguistic Science,

Faculty of Letters and Social Sciences, University of Reading,

PO Box 218, Reading 2 G6 2AA, UK

SIR-Gopnik presents ${ }^{1}$, from a linguistic viewpoint, preliminary data on dysphasia in members of a large family. The disorder is characterized as developmental dysphasia, and the basic impairment is described as one of the underlying grammar; the impaired family members are said to be "feature blind". It is misleading to present data and conclusions based on only one aspect of the dysphasia - category-specific grammatical processing - and to neglect to report that the family has a severe congenital expressive speech disorder.

At the Institute of Child Health, a comprehensive series of investigations on the same family is in progress: genetic (M. Pembrey) $)^{2}$ neurological (B. Neville), neuropsychological (our work) and speech (N. Jolleff, S. Jones, unpublished). The 29-member family, spanning three generations, includes 16 affected members.

Our investigations to date show that the affected members are impaired in repeating phonemes, words, non-words and sentences. Furthermore, they are impaired in aspects of language that are unrelated to syntax. For example, they make semantic errors in naming and they perform poorly on tests of receptive vocabulary.

Even within the domain of grammar, there is evidence that the impairment is pervasive and not specific to morphological markers, tenses and plural endings as suggested by Gopnik. As one illustration, on a test of receptive grammar ${ }^{3}$, the affected members show deficits in understanding many other types of syntactical structure, such as the reversible passive, postmodified subject, relative clause and embedded forms.

Gopnik has focused on only one aspect of the disorder, and it is inaccurate to conclude that the speech and language problem stems simply from an impairment in manipulating feature markers.

F. VARGHA-KHADEM

Institute of Child Health,

Mecklenburgh Square,

London WC1N 2AP, UK

Department of Experimental

R. E. Passingham

Psychology,

University of Oxford,

Oxford OX1 3PS, UK

1. Gopnik, M. Nature 344, 715 (1990).

2. Hurst, J.A. et al. Med. Child Neurol, 32, 347-355 (1990).

3. Bishop, D.V.M. TROG: Test for Reception of Grammar Department of Psychology, Univ. of Manchester, (1982). 